\title{
ILK predicts the efficacy of chemoradiotherapy and the prognosis of patients with esophageal squamous cell carcinoma
}

\author{
XIAO-LI MA ${ }^{1 *}$, HUA YAO ${ }^{2 *}$, XIAO WANG $^{1}$, YU WEI $^{1}$, LEI-YU CAO $^{1}$, QIAN ZHANG $^{1}$ and LI ZHANG $^{1}$ \\ ${ }^{1}$ Department of Internal Medicine VIP, The First Affiliated Hospital of Xinjiang Medical University; \\ ${ }^{2}$ Department of Health Management Center, Xinjiang Medical University, Urumqi, \\ Xinjiang Uyghur Autonomous Region 830011, P.R. China
}

Received August 20, 2018; Accepted July 17, 2019

DOI: $10.3892 / 01.2019 .10768$

\begin{abstract}
Isobaric tags for relative and absolute quantitation (iTR AQ) technology was adopted to screen differentially-expressed proteins in the serum that predict the effects of chemoradiotherapy on esophageal squamous cell carcinoma (ESCC). Thus, significantly related proteins can be functionally identified at the cellular level. A total of 60 patients diagnosed with locally advanced and advanced ESCC were recruited and treated with chemoradiotherapy. The iTRAQ technique was used to screen serum differentially expressed proteins associated with chemoradiotherapeutic efficacy. Functional identification of significantly related proteins was performed at the cellular level. Cell proliferation was detected using MTT, clonogenic and fluorescence assays, and apoptosis was assessed using flow cytometry. Transwell and wound-healing assays were used to detect the invasion and migration properties of cancer cells. Proteomics results revealed that prior to chemoradiotherapy, the expression level of integrin-linked kinase (ILK) was significantly upregulated in patients with ESCC, compared with that of the control group [ratio ( $(\mathrm{r})=4.386 ; \mathrm{P}<0.05]$, and significantly downregulated in the chemoradiotherapy-sensitive group, compared with the chemoradiotherapy-resistant group $(\mathrm{r}=0.587 ; \mathrm{P}<0.05)$. At the cellular level, the proliferation rate of cells in the experimental
\end{abstract}

Correspondence to: Dr Li Zhang, Department of Internal Medicine VIP, The First Affiliated Hospital of Xinjiang Medical University, 137 Liyushan Road, Urumqi, Xinjiang Uyghur Autonomous Region 830011, P.R. China

E-mail: 18799131188@163.com

*Contributed equally

Abbreviations: iTRAQ, isobaric tags for relative and absolute quantitation; ESCC, esophageal squamous cell carcinoma; ILK, integrin-linked kinase; CR, complete remission; PR, partial remission; SD, stability disease; $\mathrm{PD}$, progression disease; RECIST, response evaluation criteria in solid tumors

Key words: esophageal squamous cell carcinoma, proteomics, integrin-linked kinase, chemoradiotherapy group was significantly inhibited $(\mathrm{P}<0.05)$, and the number of cell colonies was decreased $(\mathrm{P}<0.01)$, while the number of apoptotic cells was significantly increased $(\mathrm{P}<0.01)$. The invasive ability of TE- 1 cells in the shILK group was significantly inhibited $(\mathrm{P}<0.01)$, and the migration rate was significantly retarded at 8 and $24 \mathrm{~h}(\mathrm{P}<0.01)$. The present study highlighted the potential value of ILK in predicting the efficacy of chemoradiotherapeutic treatment in patients with ESCC, and that ILK gene-silencing inhibits the progression of ESCC.

\section{Introduction}

Esophageal cancer is one of the most common malignancies worldwide, and in 2012, the incidence of esophageal cancer ranked 8th of all cancers (1). In 2015, cancer data from China revealed that the incidence and mortality rate of esophageal cancer were ranked 4th (2). Given that the early symptoms of esophageal cancer are not typical, and that the methods for early diagnosis are limited, $70-80 \%$ of patients cannot be diagnosed until reaching the intermediate or late stages of disease, when the opportunity for surgical treatment has been lost (3). Clinically, radiotherapy, chemotherapy and other comprehensive treatments are commonly used (4). A limited number of molecular and clinical studies have focused on the treatment of esophageal cancer in regards to the genes involved in immunization (5), and the majority of these studies have focused on adenocarcinoma at the junction of esophageal adenocarcinoma and gastric esophageal cancer, which is more frequently observed in Europe and the United States $(6,7)$.

Isobaric tags for relative and absolute quantitation (iTRAQ) is a high-throughput, high-sensitivity proteome quantification technique that is widely used for screening diagnostic and efficacy-related tumor markers $(8,9)$. In the present study, iTRAQ technology was first used to identify differentially expressed serum proteins associated with chemoradiotherapeutic efficacy in patients with esophageal squamous cell carcinoma (ESCC); the patients were recruited from different ethnic groups in the Xinjiang Uyghur Autonomous Region. Concurrently, functional tests including MTT assay, clonogenic and fluorescence assays, flow cytometry, Transwell assays and wound-healing assays were performed to determine the effect of the serum proteins with significantly differential expression, and RNA interference (RNAi) technology was used to silence the 
expression of ILK-associated gene; thus, their effects on the proliferation, apoptosis, invasion and migration of ESCC cells was observed, the results of which may be used as a reference for further research into the efficacy and prognostic mechanisms of esophageal cancer treatment.

\section{Materials and methods}

Patients. A total of 60 patients with esophageal cancer who were treated at the First Affiliated Hospital of Xinjiang Medical University between July 2008 and April 2017 were recruited into the present study. the patients were recruited from different ethnic groups (25 cases from Han, 15 cases from Kazakh and 20 cases from Uygur). A control group containing 60 age- and sex-matched subjects was also recruited; these subjects underwent physical examination at the First Affiliated Hospital of Xinjiang Medical University. The clinicopathological characteristics of the patients are shown in Table I. The patients were recruited according to the following inclusion criteria: i) Pathologically confirmed advanced IIIB-IV esophageal cancer (using the esophageal cancer Tumor-Node-Metastasis staging criteria developed by the American Joint Committee on Cancer) (10) including those with postoperative recurrence and re-grading, or who were inoperable; ii) measurable lesions; iii) aged between 18-75 years of age (male or female) with a physical performance score (WHO Performance Status) (11) $\leq 0-2$; iv) had received and tolerated radiotherapy or chemotherapy, and possessed an expected survival period $\geq 6$ months; iii) no major organ dysfunction, with normal routine blood test results (white blood cell count, neutrophil percentage, neutrophil count, hemoglobin and platelet count) and normal liver, kidney and cardiac function; and iv) were able to understand the aim of the study and give informed consent for participation.

The exclusion criteria included: i) A history of malignancy at other sites; ii) patients who were pregnant or lactating; and iii) a history of uncontrollable psychosis, diagnosed by an expert neurologist. The recruited patients received platinum-based dual chemotherapy (docetaxel combined with cisplatin or paclitaxel combined with cisplatin), of paclitaxel $\left(135-150 \mathrm{mg} / \mathrm{m}^{2}\right)$ or docetaxel $\left(75 / \mathrm{m}^{2}\right)$ plus carboplatin $(500 \mathrm{mg} /$ time $)$ or cis platinum $\left(75 \mathrm{mg} / \mathrm{m}^{2}\right)$, once every 3-4 weeks, for a total of 4-6 cycles. All patients underwent concurrent chemoradiotherapy, followed immediately by 4-6 cycles of chemotherapy. The radiotherapy program consisted of three-dimensional conformal irradiation or intensity-modulated radiation therapy, DT50-66 GY/25-33f (where the preventive and radical irradiation doses were 50 and 60-66 GY, respectively).

Short-term efficacy was categorized as complete remission (CR), partial remission (PR), stability disease (SD) and progression disease (PD) according to the response evaluation criteria in solid tumors (RECIST). The chemoradiotherapy-sensitive group was classified as $\mathrm{CR}+\mathrm{PR}+\mathrm{SD}$, and the chemoradiotherapy-resistant group as PD.

Follow-up was conducted using the telephone, outpatient consultation and medical records once every 3 months, and the follow-up deadline was July 2017. During the follow-up period, the date of death was recorded for the patients that had died. For the patients who were lost to follow-up, the final follow-up time was recorded.

Specimen collection and serum preparation. A total of $2 \mathrm{ml}$ of fasting peripheral venous blood was collected from all participants. Following collection, the samples were stored at $4^{\circ} \mathrm{C}$ for 2-3 $\mathrm{h}$ until the blood had coagulated. The samples were then centrifuged at $3,000 \mathrm{x} \mathrm{g}$ for $10 \mathrm{~min}$ at $4^{\circ} \mathrm{C}$ to isolate the serum, and the supernatants were stored at $-80^{\circ} \mathrm{C}$ until required.

Screening and identification of target proteins. The serum samples were divided into eight groups: Normal control group; esophageal cancer patients prior to treatment group; esophageal cancer patients following treatment group; radiotherapy and chemotherapy sensitive group prior to treatment; chemoradiotherapy antagonist group prior to treatment; total survival period of 1 to 2 years; total survival period 2-3 years; and total survival $>3$ years. Protein iTRAQ markers were used to identify differentially expressed proteins. After removing high-abundance proteins, such as albumin, immunoglobulin $\mathrm{G}$ and antitrypsin, a Bradford protein concentration determination assay was performed to determine the protein concentration. A total of $20 \mu \mathrm{g}$ protein was loaded on a $12.5 \%$ gel and resolved using SDS-PAGE, and proteolysis and peptide quantification were performed. A total of 8 labeled peptide samples were re-dissolved in $100 \mu \mathrm{l}$ of solvent $\left(98 \% \mathrm{H}_{2} \mathrm{O}, 0.1 \%\right.$ formic acid) and $8 \mu \mathrm{l}$ was injected into a Type C18 column size $100 \mathrm{~mm}$ x $75 \mu \mathrm{m}$, pore size $300 \mathrm{~A}$, particle size $5 \mu \mathrm{m}$. The samples were subjected to liquid phase separation using an Ultra Nano LC system (Thermo Fisher Scientific, Inc.) with a gradient of 5 to $80 \%$ buffer $\left(98 \%\right.$ acetonitrile, $2 \% \mathrm{H}_{2} \mathrm{O}$ and $0.1 \%$ formic acid) for $3 \mathrm{~h}$ at $300 \mathrm{nl} / \mathrm{min}$. Peptides were eluted using a gradient of $5-80 \%(\mathrm{v} / \mathrm{v})$ acetonitrile in $0.1 \%$ formic

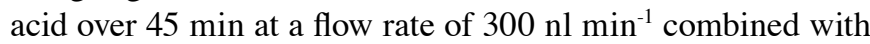
a Q-Exactive mass spectrometer (Thermo Fisher Scientific, Inc.) The eluates were directly entered the Q-Exactive mass spectrometer (Thermo Fisher Scientific, Inc.), set in positive ion mode and data-dependent manner with a full mass spectrometry scan from 350-2000 m/z, full scan resolution at 70,000 $\mathrm{MS} / \mathrm{MS}$ scan resolution at 17,500 MS/MS scan, with a minimum signal threshold of $1^{\mathrm{E}+5}$, isolation width at $2 \mathrm{Da}$. The sample was repeatedly identified 4 times. The raw mass spectrometry data was generated as a RAW file. ProteomeDiscoveral 4 software (Thermo Fisher Scientific, Inc.) was used to quantitatively analyze the peak intensity of the reported peptide ions. The results were scanned and filtered according to the misclassification rate $\leq 0.01$. A ratio $>1.2$ between the aforementioned groups was considered to indicate significant upregulation, and a ratio $<0.8$ between groups was considered to indicate significant downregulation; $\mathrm{P}<0.05$.

Integrin-linked kinase (ILK) siRNA target sequence screening and lentiviral vector construction. The ESCC EC9706 (DMEM supplemented with $10 \% \mathrm{FBS}, 37^{\circ} \mathrm{C}, 5 \% \mathrm{CO}_{2}$ ), ECa109 (RPMI-1640 supplemented with $10 \% \mathrm{FBS}$, cultured at $37^{\circ} \mathrm{C}$, $5 \% \mathrm{CO}_{2}$ ) and TE-1 (RPMI-1640 without Hepes supplemented with $10 \%$ FBS) cell lines were purchased from Shanghai Jikai Gene Chemical Technology Co., Ltd. Using the ILK gene as a template, multiple 19-21 nucleotide RNAi target sequences were designed using Chromas target sequence analysis and 
Table I. Clinicopathological characteristics of the patients.

\begin{tabular}{lcc}
\hline $\begin{array}{l}\text { Clinicopathological } \\
\text { characteristic }\end{array}$ & $\mathrm{n}$ & Proportion, \% \\
\hline $\begin{array}{l}\text { Age } \\
\leq 60\end{array}$ & 32 & 53.33 \\
$>60$ & 28 & 46.67 \\
Sex & & \\
$\quad$ Male & 35 & 58.33 \\
Female & 25 & 41.67 \\
Involved region & & \\
Neck section & 7 & 11.67 \\
Upper thoracic & 11 & 18.33 \\
Middle thoracic & 23 & 38.33 \\
Lower thoracic & 19 & 31.67 \\
Clinical stage & & \\
Phase III & & 63.33 \\
Phase IVA & 38 & 36.67 \\
\hline
\end{tabular}

design software (Technelysium Pty, Ltd., version 2.1.3). siRNAs were designed for the target gene, the target sequence was 5'-CGAAGCTCAACGAGAATCA-3', and the n.

Following RNAi target design, single-stranded DNA oligos containing interference sequences was synthesized and paired by annealing $\left(90^{\circ} \mathrm{C}\right.$ water bath for $\left.15 \mathrm{~min}\right)$ to produce double-stranded DNA. These were subsequently ligated into the lentiviral vector GV115 (Shanghai Jikai GeneChem Co., Ltd.). Prepared TOP10 competent E. coli cells (GeneChem, Inc.) were transformed using the ligation products, and PCR was used to identify positive recombinant vectors. PCR and DNA sequencing were performed on the recombinant positive clones. The upstream primer of the positive clone was amplified using Taq Plus DNA Polymerase (Vazyme BioTech Co. Ltd.). The sequences of the primers used were: Forward, CCTATTTCCCATGATTCCTTCATA, and reverse GTAATA CGGTTATCCACGCG. The thermocycling conditions were: $94^{\circ} \mathrm{C}$ for $3 \mathrm{~min}$; followed by 22 cycles of $94^{\circ} \mathrm{C}$ for $30 \mathrm{sec}$; $55^{\circ} \mathrm{C}$ for $30 \mathrm{sec} ; 72^{\circ} \mathrm{C}$ for $30 \mathrm{sec}$; and a final extension of $72^{\circ} \mathrm{C}$ for $5 \mathrm{~min}$. Sanger sequencing was used for verification. The sequencing results were compared with the correct clones for plasmid extraction. Bacteria containing the desired plasmids were transferred to $150 \mathrm{ml}$ of LB liquid medium containing ampicillin, and cultured overnight at $37^{\circ} \mathrm{C}$ with shaking. The plasmids were extracted using an EndoFree Maxi Plasmid kit according to the manufacturer's protocols and the quality was determined. Plasmids of sufficient quality, as determined using NanoDrop 2000 (Thermo Fisher Scientific, Inc.), were used for virus packaging.

Following transfection, the TE-1 cells were cultured at $37^{\circ} \mathrm{C}$, in a humidified incubator with $5 \% \mathrm{CO}_{2}$. Lentiviral particles have different affinities for different cell lines (12). First, the target cells were pre-infected with a lentivirus, and different multiplicity of infections (MOI) gradients were used to evaluate the MOI of the target cells (Data not shown). A 48-well plate was used with a total medium volume of $200 \mu 1$. For the fluorescence-tagged lentivirus infection, the infection time point was determined in the preliminary results. Green fluorescent protein expression was observed under a fluorescence microscope (magnification, x100). The fluorescence rate was $70-80 \%$, the cell confluence was approximately $80 \%$, the cells appeared healthy, the infection-efficiency was deemed sufficient, and cells were collected for further experimentation.

Reverse transcription-quantitative PCR. RNA extraction and reverse transcription-quantitative PCR (RT-qPCR) was used to analyze tumor specimen. Total RNA was extracted using the TRIzol $^{\circledR}$ (Invitrogen; Thermo Fisher Scientific, Inc.) according to the manufacturers protocol. cDNA was synthesized from $2 \mu \mathrm{g}$ total RNA using the M-MLV reverse transcriptase at $42^{\circ} \mathrm{C}$ for $1 \mathrm{~h}$ followed by $70^{\circ} \mathrm{C}$ for $10 \mathrm{~min}$. GAPDH was used as the reference gene for RT-qPCR. The sequences used in the present study were ILK forward, 5'-GACGACATTTTC ACTCAGTGCC-3' and reverse, 5'-ACGGTTCATTACATT GATCCGTG-3'; GAPDH forward, 5'-TGACTTCAACAG CGACACCCA-3' and reverse 5'-CACCCTGTTGCTGTA GCCAAA-3'. Gene-specific amplification of the $12 \mu \mathrm{l} \mathrm{PCR}$ mixture was performed using a ABI 7500HT real-time PCR system (Thermo Fisher Scientific, Inc.). The thermocycling condition were: $94^{\circ} \mathrm{C}$ for $3 \mathrm{~min}$; followed by 22 cycles of $94^{\circ} \mathrm{C}$ for $30 \mathrm{sec}, 94^{\circ} \mathrm{C}$ for $60 \mathrm{sec}$ and $72^{\circ} \mathrm{C}$ for $60 \mathrm{sec}$; followed by a final extension step at $72^{\circ} \mathrm{C}$ for $5 \mathrm{~min}$. DNA concentration was approximately doubled following each cycle of denaturation, annealing and elongation. The cycle quantification $(\mathrm{Cq})$ of each sample was calculated, and the relative expression of the gene was calculated using the $2^{-\Delta \Delta \mathrm{Cq}}$ method (13).

Cell proliferation assay. Trypsinized TE-1 cells in the logarithmic growth phase were resuspended in complete medium and plated in 96 -well culture plates at $2 \times 10^{3}$ cells/well. Cells were incubated at $37^{\circ} \mathrm{C}$ in a humidified atmosphere with $5 \% \mathrm{CO}_{2}$. The Celigo ${ }^{\circledR}$ cytometer (Nexclom Bioscience) was used to detect cell growth once a day for 5 days. By adjusting the input parameters of the analysis settings using Cellometer Auto 2000 Cell Viability Counter (Nexcelom Bioscience), the number of cells with green fluorescence was calculated and a 5-day cell proliferation curve was generated.

MTT assay. Cells in the logarithmic growth phase were harvested, homogenized into a single-cell suspension, and $2 \times 10^{3}$ cells/well were plated in 96-well cell culture plates. Cells were incubated at $37^{\circ} \mathrm{C}$ in a humidified incubator with $5 \% \mathrm{CO}_{2}$. Subsequently, $20 \mu \mathrm{l}$ MTT $(5 \mathrm{mg} / \mathrm{ml})$ was added to each well, and the cells were incubated for a further $4 \mathrm{~h}$. The supernatant was discarded, $150 \mu \mathrm{l}$ DMSO was added and the samples were shaken for 2-5 min to fully dissolve the formazan crystals. Absorbance was determined at $490 \mathrm{~nm}$ using a microplate reader. Time was used as the abscissa and the optical density was used as the ordinate for plotting the cell growth curve.

Cell colony formation assay. After transfection, TE-1 cells in the logarithmic growth phase were trypsinized in each experimental group, resuspended in complete medium and counted. The cells were seeded into a 6 -well culture plate $(500$ cells/well) and the cultured for 11 days with a media change once every 3 days. The cells were fixed with $1 \mathrm{ml} 4 \%$ paraformaldehyde 
Table II. Upregulated differentially expressed proteins in the serum of Chinese patients with esophageal cancer, before chemoradiotherapy.

\begin{tabular}{|c|c|c|c|c|}
\hline Accession ID & Protein & Gene & Ratio & P-value \\
\hline P23528 & Cofilin-1 & CFL1 & 1.532 & $1.16789 \times 10^{-3}$ \\
\hline P06753 & Tropomyosin $\alpha-3$ chain & TPM3 & 1.633 & $1.76099 \times 10^{-4}$ \\
\hline P08185 & Corticosteroid-binding globulin & SERPINA6 & 1.753 & $3.01686 \times 10^{-5}$ \\
\hline P67936 & Tropomyosin $\alpha-4$ chain & TPM4 & 1.759 & $3.61117 \times 10^{-10}$ \\
\hline Q15746 & Myosin light chain kinase, smooth muscle & MYLK & 1.76 & $2.32945 \times 10^{-2}$ \\
\hline P02749 & $\beta$-2-glycoprotein 1 & $\mathrm{APOH}$ & 1.794 & $1.68655 \times 10^{-9}$ \\
\hline $\mathrm{P} 02750$ & Leucine-rich $\alpha$-2-glycoprotein & LRG1 & 1.828 & $1.89684 \times 10^{-2}$ \\
\hline P0DJI8 & Serum amyloid A-1 protein & SAA1 & 1.836 & $3.64567 \times 10^{-9}$ \\
\hline P01019 & Angiotensinogen & AGT & 1.855 & $2.96144 \times 10^{-12}$ \\
\hline P01009 & $\alpha$-1-antitrypsin & SERPINA1 & 1.944 & $3.41166 \times 10^{-65}$ \\
\hline P68871 & Hemoglobin subunit $\beta$ & HBB & 1.951 & $3.77869 \times 10^{-12}$ \\
\hline P05155 & Plasma protease $\mathrm{C} 1$ inhibitor & SERPING1 & 2.027 & $1.03898 \times 10^{-10}$ \\
\hline $\mathrm{P} 05543$ & Thyroxin-binding globulin & SERPINA7 & 2.063 & $7.87217 \times 10^{-6}$ \\
\hline P19652 & $\alpha-1$-acid glycoprotein 2 & ORM2 & 2.065 & $1.57516 \times 10^{-7}$ \\
\hline P01023 & $\alpha$-2-macroglobulin & $\mathrm{A} 2 \mathrm{M}$ & 2.209 & $2.24553 \times 10^{-69}$ \\
\hline P04217 & $\alpha$-1B-glycoprotein & A1BG & 2.241 & $7.01006 \times 10^{-14}$ \\
\hline P0DJI9 & Serum amyloid A-2 protein & SAA2 & 2.254 & $7.76843 \times 10^{-16}$ \\
\hline P01011 & $\alpha$-1-antichymotrypsin & SERPINA3 & 2.363 & $1.59357 \times 10^{-28}$ \\
\hline P02768 & Serum albumin & ALB & 2.477 & $1.89258 \times 10^{-3}$ \\
\hline P02741 & C-reactive protein & CRP & 2.517 & $1.59305 \times 10^{-91}$ \\
\hline P01861 & Immunoglobulin heavy constant $\gamma 4$ & IGHG4 & 2.584 & $2.27127 \times 10^{-3}$ \\
\hline P02787 & Serotransferrin & $\mathrm{TF}$ & 2.89 & $5.56713 \times 10^{-82}$ \\
\hline P02790 & Hemopexin & HPX & 2.999 & $5.72798 \times 10^{-31}$ \\
\hline $\mathrm{P} 25311^{\mathrm{a}}$ & Zinc- $\alpha$-2-glycoprotein & AZGP1 & 3.122 & $5.90489 \times 10^{-8}$ \\
\hline Q13418 & Integrin-linked protein kinase & ILK & 4.386 & $3.69519 \times 10^{-31}$ \\
\hline $\mathrm{P} 02763^{\mathrm{a}}$ & $\alpha-1$-acid glycoprotein 1 & ORM1 & 5.234 & $5.50575 \times 10^{-16}$ \\
\hline
\end{tabular}

aignificantly differentially expressed protein. The results are compared with the those of the control group.

at $37^{\circ} \mathrm{C}$ for $30-60 \mathrm{~min}$ and stained with $500 \mu \mathrm{l}$ Giemsa staining solution (Shanghai Dingguo Biotechnology Co., Ltd.) at $37^{\circ} \mathrm{C}$ for 10-20 min and the colonies were subsequently counted.

Apoptosis detection using flow cytometry. Following transfection, cells in the logarithmic growth from each experimental group were harvested and resuspended in complete culture medium. The cells were collected by centrifugation at $1,300 \mathrm{xg}$ for $5 \mathrm{~min}$ at $4^{\circ} \mathrm{C}$, the supernatant was discarded, and the cell pellet was washed with pre-cooled D-Hanks (Shanghai Research Extension Biotechnology Co., Ltd.) solution at $4^{\circ} \mathrm{C}$. The cell pellet was washed with binding buffer (Shanghai Suo Laibao Biotechnology Co., Ltd, ) stained with $10 \mu \mathrm{l}$ Annexin V-APC and analyzed using a flow cytometer and Guava ${ }^{\circledR}$ InCyte version 8 HT (Luminex Corporation).

Transwell migration and invasion assay. A total of $1 \times 10^{5}$ cells/well were seeded on a Matrigel membrane in the upper chamber of a 24-well Transwell plates for the invasion assay. For the migration assay cells were seeded without Matrigel. In the bottom chamber, $600 \mu 1$ medium containing
$30 \%$ FBS was added. Cells were incubated under standard culture conditions for $20 \mathrm{~h}$. Following invasion or migration, cells which had not invaded or migrated were removed and the remaining cells were stained with $800 \mu \mathrm{l}$ of Giemsa staining solution onto the lower surface of the membrane at $37^{\circ} \mathrm{C}$ for 3-5 min. The membranes were visualized under a light microscope at $\mathrm{x} 200$ and imaged to determine differences in the migratory and invasive capacity. A total of 9 random microscopic fields for each well were counted.

Wound-healing assay. Transfected cells $\left(\sim 4 \times 10^{4}\right)$ from each group were added to 96-well plates, and cultured until $\sim 90 \%$ confluent. The following day, the concentration of serum in the medium was reduced, and a wound was created in the monolayer. The cells were gently rinsed 2-3 times with serum-free medium, and incubated at $37^{\circ} \mathrm{C}$ in a humidified incubator with $5 \% \mathrm{CO}_{2}$. Images were captured at 0,8 and $24 \mathrm{~h}$ using a fluorescence microscope (magnification, x200). Images were obtained after 0,8 and $24 \mathrm{~h}$ using a light microscope (magnification, $x 200$ ). The width of the scratched area in the picture at each time point of each wound was obtained using the $\mathrm{W}$ value function of Adobe Photoshop (Adobe Systems Europe, Ltd. 
Table III. Downregulated differentially expressed proteins in the serum of Chinese patients with esophageal cancer, before chemoradiotherapy.

\begin{tabular}{lllll}
\hline Accession ID & \multicolumn{1}{c}{ Protein } & \multicolumn{1}{c}{ Gene } & Ratio & \multicolumn{1}{c}{ P-value } \\
\hline P02776 & Platelet factor 4 & PF4 & 0.469 & $2.12173 \times 10^{-21}$ \\
Q08380 & Galectin-3-binding protein & LGALS3BP & 0.483 & $4.59282 \times 10^{-40}$ \\
P08697 & $\alpha$-2-antiplasmin & SERPINF2 & 0.495 & $2.5819 \times 10^{-30}$ \\
P10720 & Platelet factor 4 variant & PF4V1 & 0.533 & $1.24972 \times 10^{-7}$ \\
P02751 & Fibronectin & FN1 & 0.536 & $1.72558 \times 10^{-110}$ \\
Q16610 & Extracellular matrix protein 1 & ECM1 & 0.557 & $8.40852 \times 10^{-11}$ \\
Q13103 & Secreted phosphoprotein 24 & SPP2 & 0.565 & $2.66878 \times 10^{-7}$ \\
P27918 & Properdin & CFP & 0.582 & $1.6419 \times 10^{-16}$ \\
P00488 & Coagulation factor XIII A chain & F13A1 & 0.594 & $1.3398 \times 10^{-14}$ \\
Q5SYB0 & FERM and PDZ domain-containing protein 1 & FRMPD1 & 0.607 & $2.98852 \times 10^{-12}$ \\
Q15485 & Ficolin-2 & FCN2 & 0.608 & $1.51904 \times 10^{-17}$ \\
O43852 & Calumenin & CALU & 0.61 & $4.42339 \times 10^{-8}$ \\
P01860 & Immunoglobulin heavy constant $\gamma 3$ & IGHG3 & 0.639 & $1.20085 \times 10^{-16}$ \\
P04114 & Apolipoprotein B-100 & APOB & 0.641 & $4.42101 \times 10^{-70}$ \\
O43866 & CD5 antigen-like & CD5L & 0.642 & $6.51383 \times 10^{-21}$ \\
Q92954 & Proteoglycan 4 & PRG4 & 0.651 & $3.50318 \times 10^{-5}$ \\
P04004 & Vitronectin & VTN & 0.658 & $4.9004 \times 10^{-179}$ \\
P04180 & Phosphatidylcholine-sterol acyltransferase & LCAT & 0.665 & $5.75865 \times 10^{-10}$ \\
P04196 & Histidine-rich glycoprotein & HRG & 0.666 & $5.28207 \times 10^{-20}$ \\
Q96IY4 & Carboxypeptidase B2 & CPB2 & 0.667 & $8.99551 \times 10^{-8}$ \\
\hline
\end{tabular}

aSignificantly differentially expressed protein. The results are compared with the those of the control group.

version CC 2018). Wound closure was measured relative to the starting wound width by dividing the wound width at each time point by the width at the start.

Statistical analysis. Statistical data analysis was conducted using SPSS version 19.0 software (IBM Corp.). A Student's t-test was used to compare differences between two groups. Comparisons between shILK and shCtrl were initially analyzed using an F-test (homogeneity of variance test). If the F-test value is $>0.05$, a t-test value was obtained using an equal variance two-sample test. If the F-test value was $<0.05$, the heteroscedasticity was doubled. The sample test yielded the t-test value. $\mathrm{P}<0.05$ was considered to indicate a statistically significant difference.

\section{Results}

Evaluation of clinical efficacy. According to RECIST, 36 cases were included in the $\mathrm{CR}+\mathrm{PR}+\mathrm{SD}$ group by analyzing medical data from outpatient visits records, which accounted for $60 \%$ of the total cases; 24 cases were classified as PD, $40 \%$ of the total.

Differentially expressed serum proteins in patients with ESCC. From the patients with ESCC, 46 differentially expressed proteins were identified prior to chemoradiotherapy, compared to those identified in the control subjects: 26 proteins were upregulated and 20 were downregulated (Tables II and III).

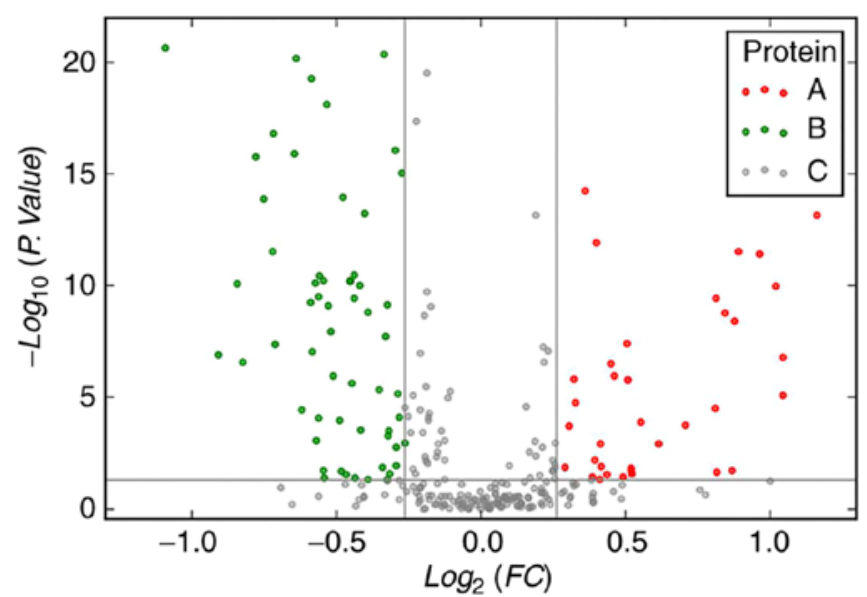

Figure 1. Distribution of differentially expressed serum proteins in Chinese patients with esophageal cancer before chemoradiotherapy, compared with the control group. A represents proteins with a $>1.2$-fold change increase in expression. $\mathrm{B}$ represents proteins with a $>0.833$-fold change decrease in expression. $\mathrm{C}$ represents proteins which were not determined to be significantly differentially expressed based on the cut-off criteria. FC, fold change.

Volcano maps show that differential expression of serum proteins between patients with ESCC (before chemoradiotherapy) and those in the control group (Fig. 1).

Significantly differentially expressed proteins were compared between the chemoradiotherapy-sensitive and -resistant groups and between the survival times of patients 
Table IV. Differentially expressed proteins between Chinese chemoradiotherapy-sensitive and chemoradiotherapy-resistant patients with esophageal cancer.

\begin{tabular}{|c|c|c|c|c|c|}
\hline Accession ID & Protein & Gene & Ratio & P-value & Regulation \\
\hline P02763 & $\alpha$-1-acid glycoprotein 1 & ORM1 & 0.348 & $1.00117 \times 10^{-13}$ & Down \\
\hline P00738 & Haptoglobin & $\mathrm{HP}$ & 0.456 & $4.58182 \times 10^{-21}$ & Down \\
\hline $\mathrm{P} 01833^{\mathrm{a}}$ & Polymeric immunoglobulin receptor & PIGR & 0.526 & $1.30577 \times 10^{-2}$ & Down \\
\hline P04217 & $\alpha$-1B-glycoprotein & A1BG & 0.653 & $1.50285 \times 10^{-20}$ & Down \\
\hline P25311 & Zinc- $\alpha$-2-glycoprotein & AZGP1 & 0.656 & $2.97886 \times 10^{-6}$ & Down \\
\hline P08571 & Monocyte differentiation antigen CD14 & CD14 & 0.657 & $1.63716 \times 10^{-3}$ & Down \\
\hline P11597 & Cholesteryl ester transfer protein & CETP & 0.661 & $9.93464 \times 10^{-6}$ & Down \\
\hline Q13418 & Integrin-linked kinase & ILK & 0.587 & $9.41968 \times 10^{-4}$ & Down \\
\hline A0M8Q6 ${ }^{\mathrm{a}}$ & $\operatorname{Ig} \lambda-7$ chain $\mathrm{C}$ region & IGLC7 & 1.886 & $3.64692 \times 10^{-3}$ & Up \\
\hline Q15848 & Adiponectin & ADIPOQ & 1.836 & $9.54065 \times 10^{-9}$ & Up \\
\hline P59665 & Neutrophil defensin 1 & DEFA1 & 1.927 & $1.16427 \times 10^{-2}$ & Up \\
\hline
\end{tabular}

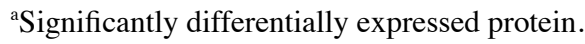

Table V. Differentially expressed proteins between Chinese patients with esophageal cancer with $>3$ years and 1-2 years survival rates.

\begin{tabular}{|c|c|c|c|c|c|}
\hline Accession ID & Description & Gene & Ratio & $\mathrm{P}$-value & Regulation \\
\hline $\mathrm{P} 05154^{\mathrm{a}}$ & Plasma serine protease inhibitor & SERPINA5 & 0.421 & $4.45068 \times 10^{-18}$ & Down \\
\hline Q92496 & Complement factor H-related protein 4 & CFHR4 & 0.558 & $5.80371 \times 10^{-11}$ & Down \\
\hline P59665 & Neutrophil defensin 1 & DEFA1 & 0.58 & $5.35236 \times 10^{-3}$ & Down \\
\hline P62805 ${ }^{\mathrm{a}}$ & Histone H4 & HIST1H4A & 0.584 & $1.79658 \times 10^{-6}$ & Down \\
\hline P68431 ${ }^{\mathrm{a}}$ & Histone H3.1 & HIST1H3A & 0.596 & $1.23326 \times 10^{-3}$ & Down \\
\hline P20160 & Azurocidin & AZU1 & 0.606 & $2.56589 \times 10^{-4}$ & Down \\
\hline Q13418 & Integrin-linked kinase & ILK & 0.633 & $1.45967 \times 10^{-2}$ & Down \\
\hline P02776 & Platelet factor 4 & PF4 & 0.664 & $5.87470 \times 10^{-17}$ & Down \\
\hline P49720 & Proteasome subunit $\beta$ type- 3 & PSMB3 & 1.552 & $1.44523 \times 10^{-2}$ & Up \\
\hline P0DJI9a & Serum amyloid A-2 protein $\mathrm{OS}=\mathrm{Homo}$ & SAA2 & 1.68 & $1.57258 \times 10^{-13}$ & Up \\
\hline
\end{tabular}

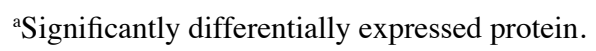

with ESCC, classified as either 1-2, 2-3 and >3 years (Tables IV and V). The volcano plots show differential expression of serum proteins between patients with esophageal cancer of different severities group (Fig. 2).

Among the differentially-expressed proteins, ILK appeared most frequently at all outcomes in patients with esophageal cancer. This protein was upregulated in patients with ESCC before chemoradiotherapy, compared with the control group [ratio $(\mathrm{r})=4.386 ; \mathrm{P}<0.05$ ], and downregulated in the chemoradiotherapy-sensitive group compared with the chemoradiotherapy-resistant group $(\mathrm{r}=0.587, \mathrm{P}<0.05$; survival period $>3$ years compared with a survival period of $1-2$ years; $\mathrm{r}=0.633, \mathrm{P}<0.05$; Table VI).

The effect of ILK expression on cell proliferation, apoptosis, invasion and migration in ESCC. The ILK mRNA expression levels were determined in the TE-1 ESCC cell line (Fig. 3). Lentivirus was used for target cell transfection, and the results

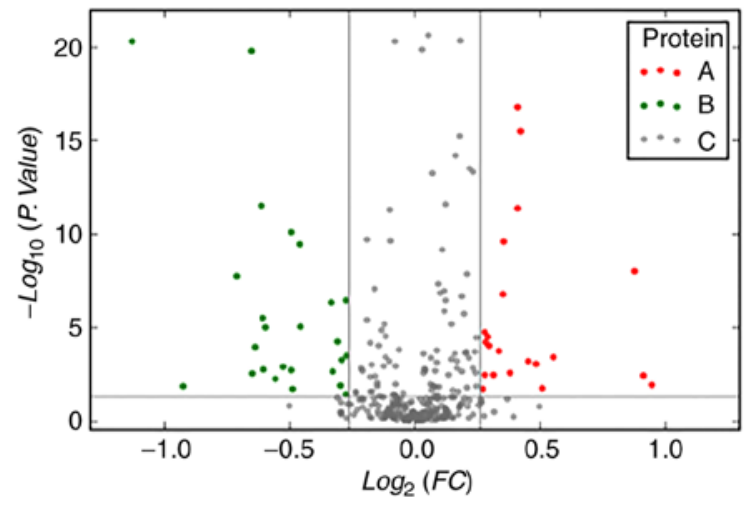

Figure 2. Distribution of differentially expressed proteins between chemoradiotherapy-sensitive and chemoradiotherapy-resistant groups in Chinese patients with esophageal cancer. A represents proteins with a $>1.2$-fold change increase in expression. $\mathrm{B}$ represents proteins with a $>0.833$-fold change decrease in expression. $\mathrm{C}$ represents proteins which were not determined to be significantly differentially expressed based on the cut-off criteria. FC, fold change. 
Table VI. Expression of ILK in Chinese patients with esophageal cancer of different severities.

\begin{tabular}{lcccccc}
\hline Group & Accession & Description & Gene & Ratio & P-value & Regulation \\
\hline $\begin{array}{l}\text { Esophageal cancer patients prior } \\
\text { to treatment vs. control group }\end{array}$ & Q13418 & Integrin-linked kinase & ILK & 4.386 & $3.69519 \times 10^{-31}$ & Up \\
$\begin{array}{l}\text { Chemoradiotherapy-sensitive } \\
\text { group vs. chemoradiotherapy- }\end{array}$ & Q13418 & Integrin-linked kinase & ILK & 0.587 & $9.41968 \times 10^{-4}$ & Down \\
$\begin{array}{l}\text { resistant group } \\
\begin{array}{l}\text { Survival group }>3 \text { years vs. } \\
\text { survival group 1-2 years }\end{array}\end{array}$ & Q13418 & Integrin-linked kinase & ILK & 0.633 & $1.45967 \times 10^{-2}$ & Down \\
\hline
\end{tabular}

Upregulated ratio $>1.2$, downregulated ratio $<0.8$.

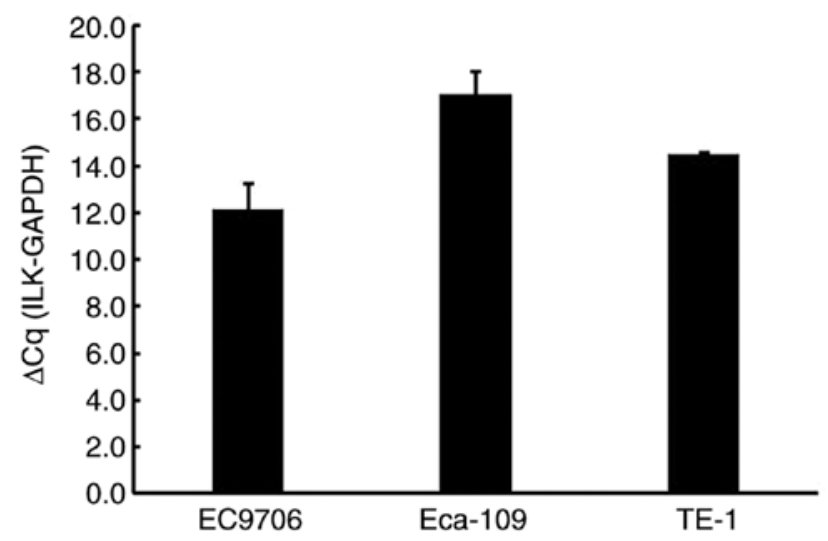

Figure 3. Reverse transcription-quantitative PCR results of ILK expression levels indicate that ILK is expressed in EC9706, Eca-109 and TE-1 esophageal squamous cell carcinoma cells. GAPDH was used as the internal control. ILK, integrin-linked kinase.

confirmed a transfection efficiency of $>80 \%$. Following transfection, there were no noticeable changes in the morphology and the cells appeared healthy. After siRNA lentivirus infection, the mRNA expression level of ILK was determined using RT-qPCR. The results showed that the expression of ILK in TE-1 cells of the shILK group was successfully inhibited compared with the shCtrl group $(\mathrm{P}<0.05)$, and that the knockdown efficiency was $88 \%$ (Fig. 4).

To examine the effect of ILK gene ablation on cell proliferation, cell number was determined using fluorescence and MTT assays three days post-transfection with shRNA lentivirus. After five days, the proliferation rate was decreased in the shILK group compared with the shCtrl group $(\mathrm{P}<0.05)$ in both assays (Figs. 5 and 6). ILK gene-silencing was shown to inhibit the proliferation of TE-1 cells.

Flow cytometry was used to detect the impact of ILK gene inhibition on apoptosis, five days following shRNA lentivirus transfection. The degree of apoptosis in TE-1 cells of the shILK group increased significantly $(\mathrm{P}<0.01)$, indicating that the ILK gene is significantly associated with apoptosis in these cells (Fig. 7).

In addition, the impact of ILK gene ablation on cell colony formation was also detected. The number of TE-1 cell colonies in the shILK group was significantly lower than that of the shCtrl group $(\mathrm{P}<0.01)$, suggesting that the ILK gene is

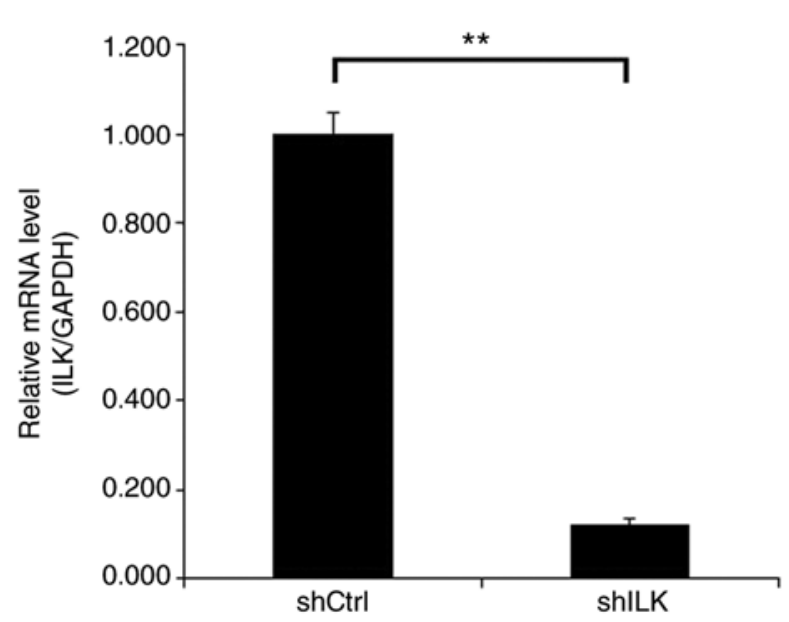

Figure 4. Comparison of mRNA expression levels between TE-1 cells transfected with small interfering RNA lentivirus and the control group. ${ }^{* *} \mathrm{P}<0.01$. ILK, integrin-linked kinase; ctrl, control.

significantly associated with the colony forming ability of TE-1 cells (Fig. 8).

Migration and invasion assays were used to detect the effect of ILK-knockdown on migration and invasion capacities of TE-1 cells, three days post-transfection with shRNA lentivirus. The migration and invasion abilities of TE-1 cells in the shILK group were significantly inhibited compared with those of the shCtrl group $(\mathrm{P}<0.01)$, suggesting that ILK gene-silencing inhibits the migration and invasion abilities of TE-1 cells (Figs. 9 and 10).

The effect of ILK gene-silencing on TE-1 cell migration was also detected using a wound-healing assay three days post-transfection with shRNA lentivirus. The migratory ability at 8 and $24 \mathrm{~h}$ in the shILK group compared with the shCtrl group at the same time point was significantly reduced $(\mathrm{P}<0.01)$, suggesting that ILK is significantly associated with the migratory ability of TE-1 cells (Fig. 11).

\section{Discussion}

According to China's esophageal cancer and the USA National Cancer Comprehensive Network guidelines, advanced ESCC is primarily treated with chemoradiotherapy-based comprehensive treatment (14). However, resistance to chemoradiotherapy 

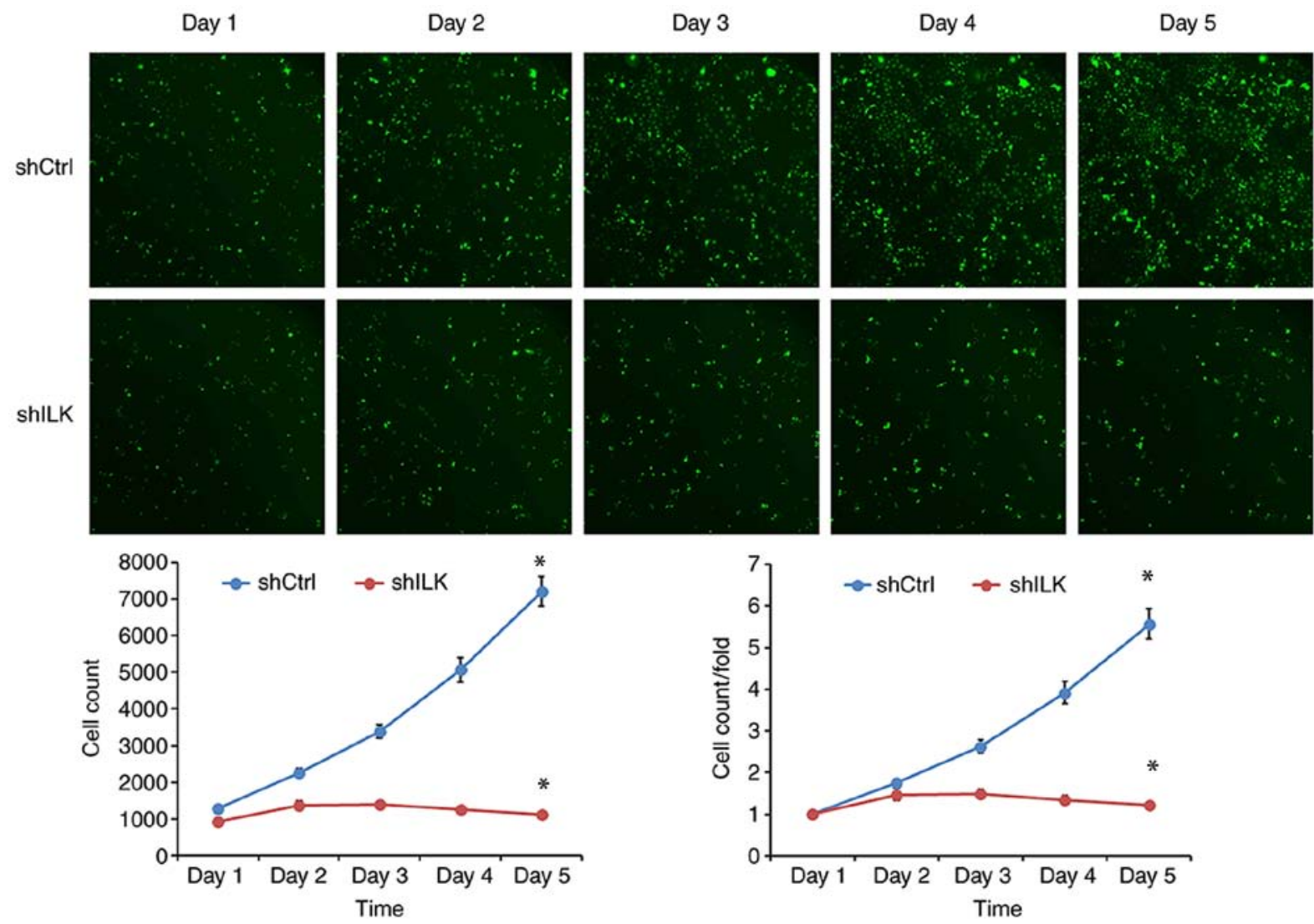

Figure 5. Effects of ILK knockdown on esophageal squamous-cell carcinoma cell proliferation using the Celigo ${ }^{\circledR}$ cytometer..P $<0.05$. sh, short hairpin; ILK, integrin-linked kinase; ctrl, control.


Figure 6. Effects of ILK knockdown on esophageal squamous-cell carcinoma cell proliferation, determined using an MTT assay..P $<0.05$. sh, short hairpin; ILK, integrin-linked kinase; ctrl, control; OD, optical density.

is the primary reason for its limited effect, which results in poor overall efficacy (15). Studies in China and worldwide have suggested that the abnormal expression of molecular markers, such as cell division cycle 25C (16), suppressor of cytokine signaling 1 (17), single-minded homolog 2 (18) and phosphatidylinositol-4,5-bisphosphate 3-kinase catalytic subunit $\alpha$ (19) in esophageal cancer tissues has significance when predicting the efficacy of esophageal cancer chemotherapy. However, to date, there are no established molecular markers for predicting the efficacy of esophageal cancer chemotherapy.
In the present study, iTRAQ technology was used to screen serum differentially-expressed proteins associated with the efficacy of chemoradiotherapy in ESCC. The results revealed that ILK expression levels in patients with esophageal cancer (before chemoradiotherapy) were higher compared with those in the control subjects, and that ILK expression in chemoradiotherapy-sensitive patients was reduced compared with that in the chemoradiotherapy-resistant group. These findings indicated that the abnormal expression of ILK may be associated with the occurrence and development of ESCC, 

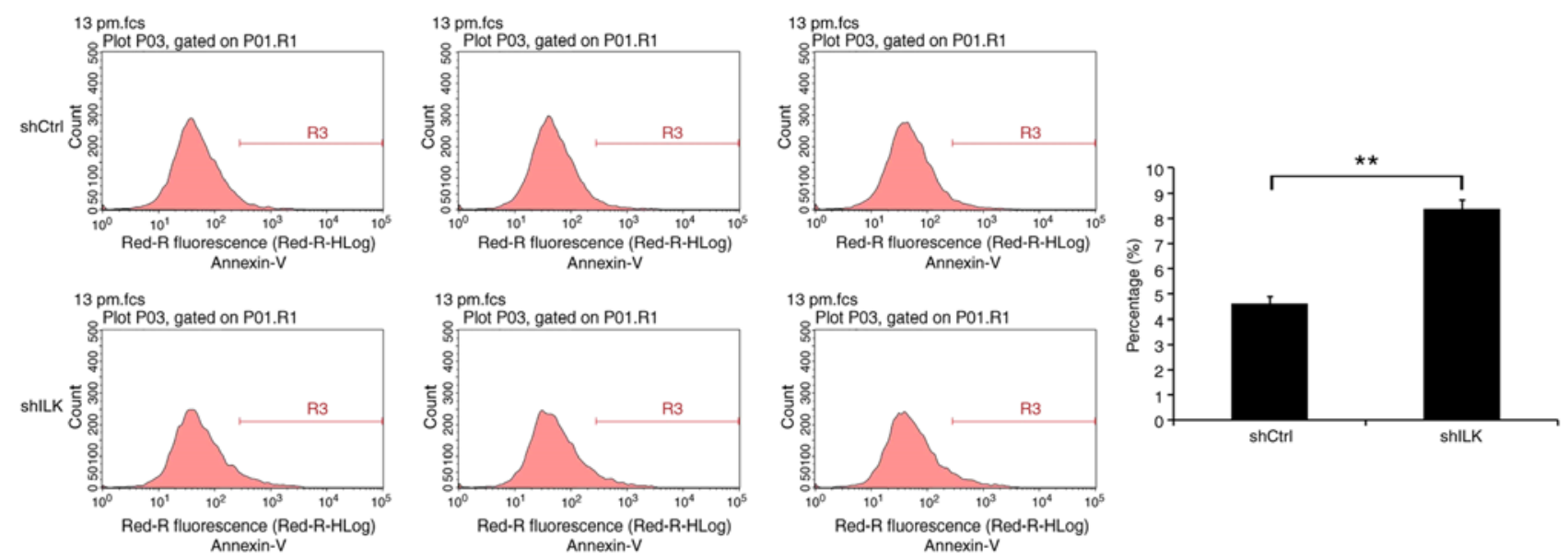

Figure 7. Effects of ILK knockdown on apoptosis in esophageal squamous-cell carcinoma cells, using flow cytometry. ${ }^{* *} \mathrm{P}<0.01$. sh, short hairpin; ILK, integrin-linked kinase; ctrl, control.
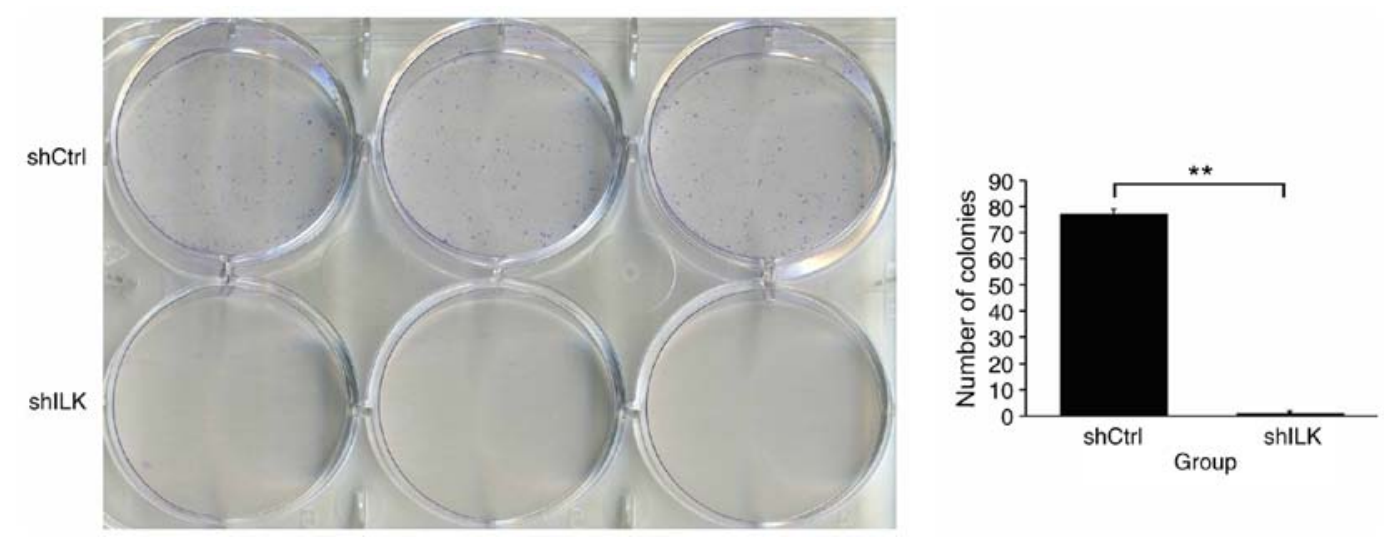

Figure 8. Effects of ILK knockdown on esophageal squamous-cell carcinoma cell colony formation. ${ }^{* *} \mathrm{P}<0.01$. sh, short hairpin; ILK, integrin-linked kinase; ctrl, control.
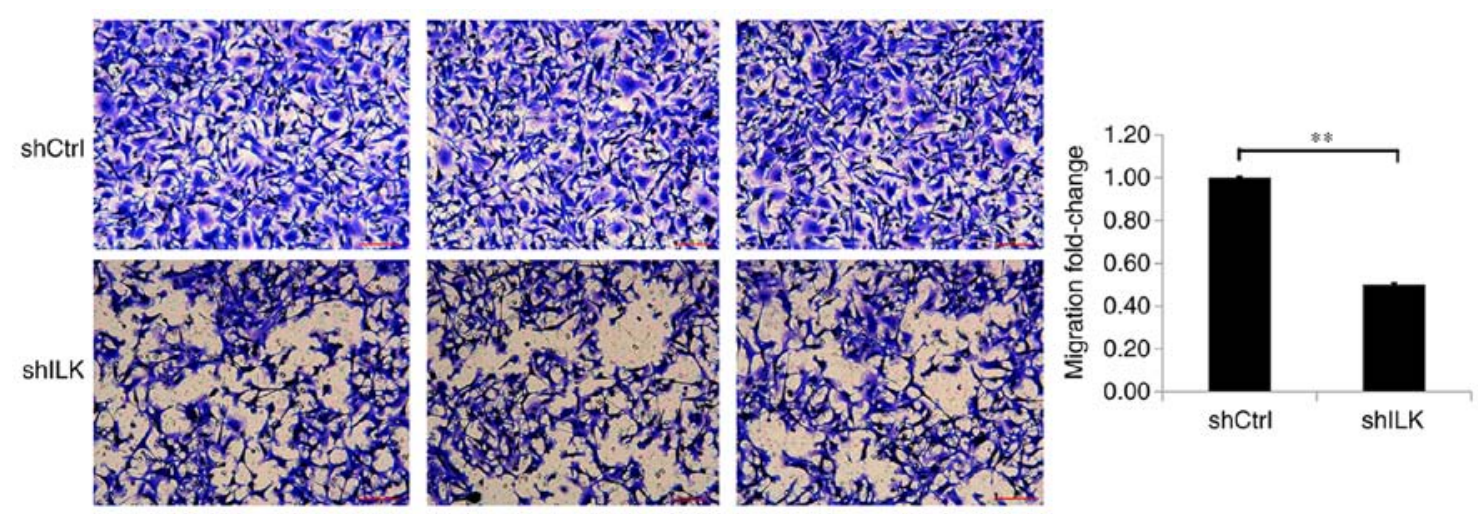

Figure 9. Effects of ILK knockdown on esophageal squamous-cell carcinoma cell migration, using Transwell assays. ${ }^{* *} \mathrm{P}<0.01$. sh, short hairpin; ILK, integrin-linked kinase; ctrl, control. Magnification, x200.

and that ILK may be involved in the regulation of chemoradiotherapy sensitivity, and thus closely associated with sensitivity to chemoradiotherapy in patients with esophageal cancer. Based on these results, the effect of ILK expression on ESCC cells characteristics was investigated. To the best of our knowledge, the present study shows for the first time that ILK gene-silencing significantly inhibits the proliferation, invasion and migration, and promotes apoptosis in ESCC TE-1 cells.

ILK is a serine/methionine protein kinase that was discovered by Hannigan et al (20) in a double yeast hybridization screening experiment in human cDNA libraries, using the $\beta 1$ integrin cytoplasmic domain. As a key kinase in integrin and growth factor receptor signaling pathways, ILK regulates cell 

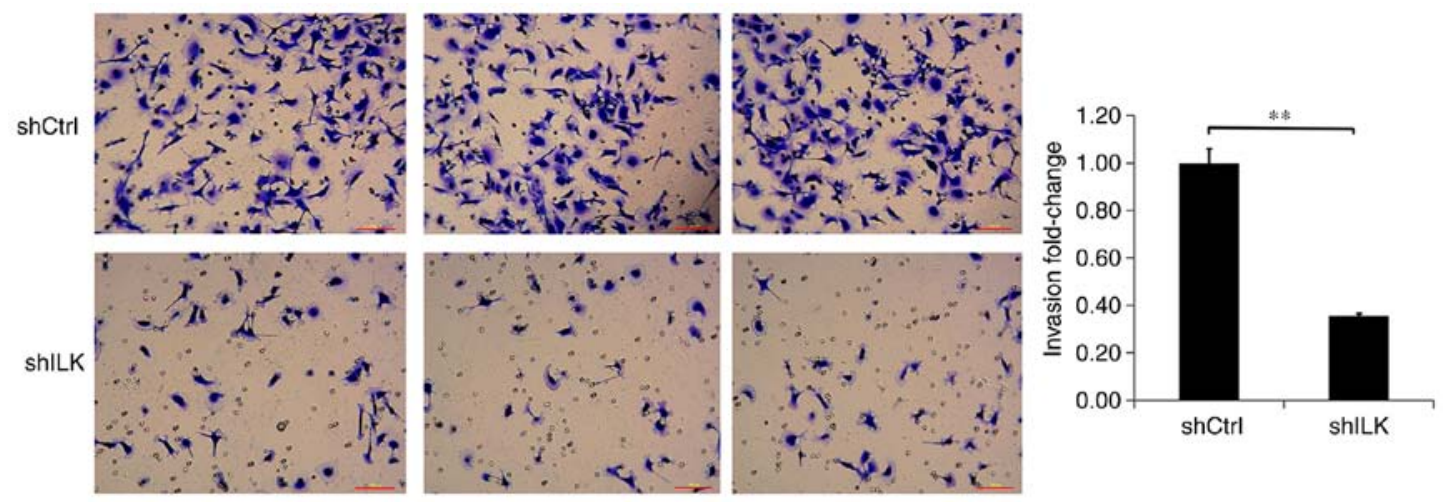

Figure 10. Effects of ILK knockdown on esophageal squamous-cell carcinoma cell invasion, using a Matrigel assay. ${ }^{* *} \mathrm{P}<0.01$. sh, short hairpin; ILK, integrin-linked kinase; ctrl, control. Magnification, 200x.

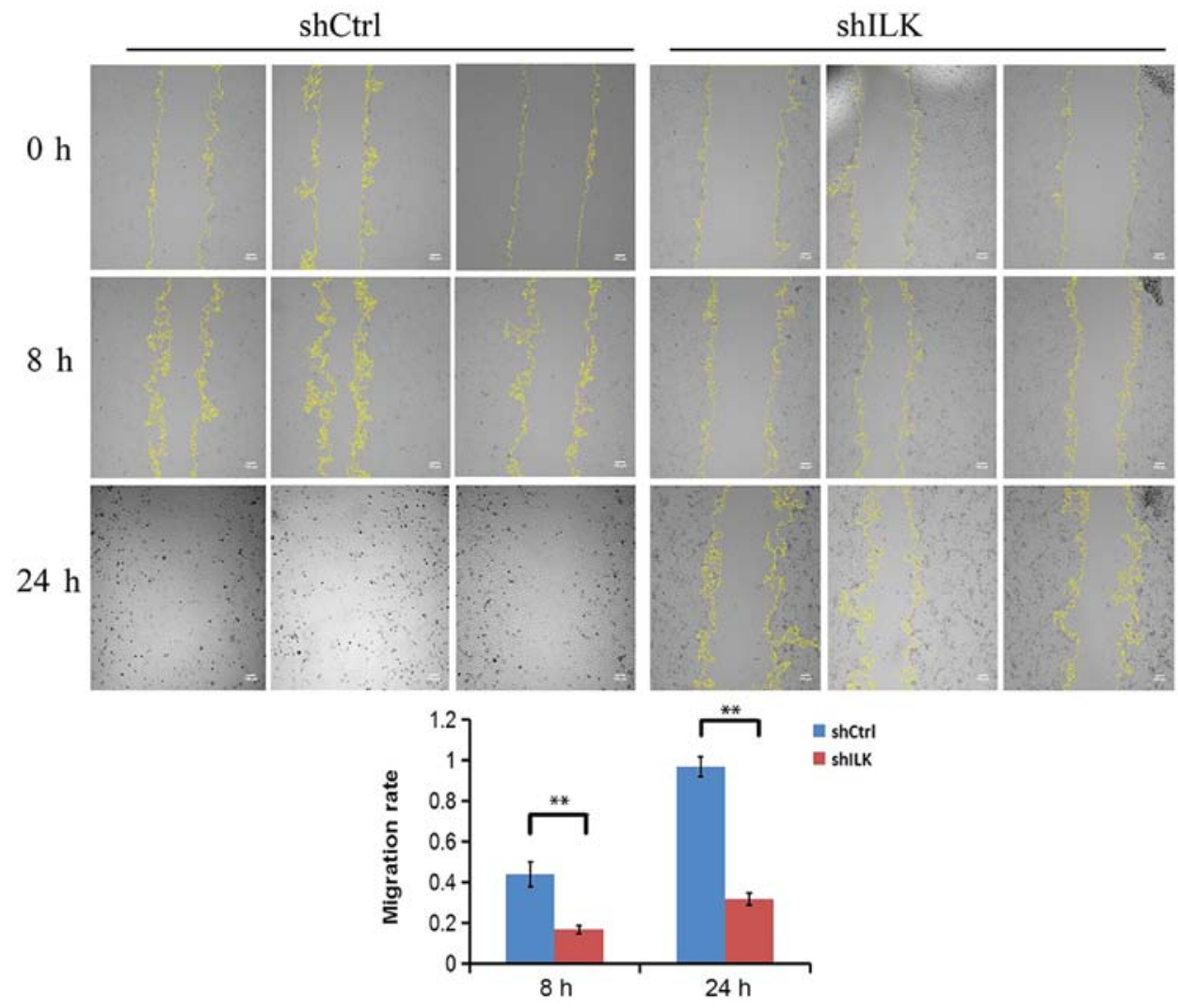

Figure 11.Effects of ILK knockdown on esophageal squamous-cell carcinoma cell migration, using wound-healing assays. sh, short hairpin; ILK, integrin-linked kinase; ctrl, control. ${ }^{* *} \mathrm{P}<0.01$ vs. the respective shCtrl. Magnification, 200x.

growth, differentiation, adhesion and apoptosis, and is closely associated with tumor formation, invasion, and metastasis (21). Furthermore, ILK upregulation has been reported to occur in bladder (22) and colon cancer (23). Regarding ILK research in esophageal cancer, Driver and Veale (24) used RT-PCR to study the expression and subtypes of ILK, epidermal growth factor and transforming growth factor- $\beta 1$ in five human ESCC cell lines of South African origin. The effect of ILK expression suggests that epidermal growth factor and transforming growth factor- $\beta 1$ may regulate ILK expression in ESCC.

The present study suggested that cell proliferation was reduced when ILK expression was inhibited in TE-1 cells, as shown by fluorescence detection, MTT and colony formation assays. These findings suggest that ILK may promote the proliferation of TE-1 cells. Abnormal expression of the ILK gene may be an important factor to increase the malignancy of ESCC. Apoptosis is closely associated with the occurrence, development and prognosis of various diseases, particularly tumors (25). The effect of ILK gene inhibition on apoptosis in TE-1 cells was assessed using flow cytometry. The apoptotic rate of TE-1 cells was increased relative to the control group following ILK knockdown. Therefore, ILK inhibits apoptosis and may be an important factor for the proliferation of TE-1 cells. Furthermore, wound-healing assays revealed that ILK inhibited the migratory ability of TE-1 cells compared with that of the control group. It was hypothesized that ILK may promote the migration of TE-1 cells, leading to enhanced biological characteristics and increasing the risk of distant 
metastasis in malignant tumors. To simulate the invasive tumor cell environment, a Transwell chamber was utilized. The results showed that ILK silencing inhibited the invasive properties of TE-1 cells, and therefore, ILK may promote the invasion of ESCC cells.

In addition, studies have reported that abnormal expression of ILK affects the chemoradiotherapeutic sensitivity of tumor cells. Duxbury et al (26) found that overexpression of ILK increased the chemotherapeutic resistance of pancreatic cancer cells to gemcitabine, and that ILK knockout increased the sensitivity of caspase-3-mediated apoptosis to gemcitabine. A previous study by Lanvin et al (27) showed that ILK regulated mitochondrial death caused by radiotherapy via the hypoxia inducible factor- $1 \alpha$ and survivin pathways, thereby altering the radiosensitivity of glioma cells. These studies suggest that ILK increases tumor cell resistance to radiotherapy. However, there is no experimental indication that ILK influences the chemoradiotherapeutic sensitivity of esophageal cancer.

In the present study, iTRAQ technology was used to identify the molecular marker ILK, which is predictive of the efficacy of esophageal cancer chemotherapy. It was revealed for the first time that the inhibition of ILK expression promoted the biological characteristics of ESCC, and increased the degree of tumor malignancy. However, the present study has several limitations and was not able to determine the mechanism by which ILK promotes the characteristics of ESCC; therefore, further research is required. Moreover, proteins associated with metastasis were not investigated, and the lack of animal studies and the investigation of proteins associated with epithelial-mesenchymal transition are also limitations of the present study. In addition, 2-dimensional migration and invasion cannot fully recapitulate the metastatic phenotype. At the same time, ILK is a potential mediator of tumor chemoradiotherapy resistance. Therefore, in the future, an in-depth understanding of the molecular mechanisms of resistance to esophageal cancer chemoradiotherapy, and the exploration of new strategies for targeting chemoradiotherapy resistance, will have important clinical implications for improving treatment efficacy and patient survival.

\section{Acknowledgements}

Not applicable.

\section{Funding}

The present study was supported by funding from the National Science Foundation of China (grant no. 81860421).

\section{Availability of data and materials}

The datasets used and/or analyzed during the current study are available from the corresponding author on reasonable request.

\section{Authors' contributions}

XLM, HY and LZ performed the experiments, analyzed the data and wrote the manuscript. XW, YW, LYC and QZ performed the experiments and analyzed the data. XLM and LZ contributed to the design of the study and the experiments, and wrote the manuscript. All authors read and approved the final version of the manuscript.

\section{Ethics approval and consent to participate}

All patients agreed to participate in the present study, and written consent was obtained from each patient. The research protocol was approved by the institutional review committee of the First Affiliated Hospital of Xinjiang Medical University.

\section{Patient consent for the publication}

All patients provided written informed consent for the publication of any associated data and accompanying images.

\section{Competing interests}

The authors declare that they have no competing interests.

\section{References}

1. Soerjomataram I, Lortet-Tieulent J, Parkin DM, Ferlay J, Mathers C, Forman D and Bray F: Global burden of cancer in 2008: A systematic analysis of disability-adjusted life-years in 12 world regions. Lancet 380: 1840-1850, 2012.

2. Chen W, Zheng R, Baade PD, Zhang S, Zeng H, Bray F, Jemal A, $\mathrm{Yu}$ XQ and He J: Cancer statistics in China, 2015. CA Cancer J Clin 66: 115-132, 2016.

3. Napier KJ, Scheerer M and Misra S: Esophageal cancer: A Review of epidemiology, pathogenesis, staging workup and treatment modalities. World J Gastrointest Oncol 6: 112-120, 2014.

4. Jemal A, Clegg LX, Ward E, Ries LA, Wu X, Jamison PM, Wingo PA, Howe HL, Anderson RN and Edwards BK: Annual report to the nation on the status of cancer, 1975-2001, with a special feature regarding survival. Cancer 101: 3-27, 2004.

5. Doi T, Piha-Paul SA, Jalal SI, Saraf S, Lunceford J, Koshiji M and Bennouna J: Safety and antitumor activity of the anti-programmed death-1 antibody pembrolizumab in patients with advanced esophageal carcinoma. J Clin Oncol 36: 61-67, 2018.

6. Pennathur A, Gibson MK, Jobe BA and Luketich JD: Oesophageal carcinoma. Lancet 381: 400-412, 2013.

7. Giri S, Pathak R, Aryal MR, Karmacharya P, Bhatt VR and Martin MG: Incidence trend of esophageal squamous cell carcinoma: An analysis of Surveillance Epidemiology and End Results (SEER) database. Cancer Causes Control 26: 159-161, 2015.

8. Zhang J, Zhi C, Zhen F, Yuan X, Jiao C, Zhu H, Zhu H and Feng Y: iTRAQ-based quantitative proteomic analyses of high grade esophageal squamous intraepithelial neoplasia. Proteomics Clin Appl: Dec 11, 2017 (Epub ahead of print). doi: 10.1002/prca.201600167.

9. Hsu CH, Hsu CW, Hsueh C, Wang CL, Wu YC, Wu CC, Liu CC Yu JS, Chang YS and Yu CJ: Identification and characterization of potential biomarkers by quantitative tissue proteomics of primary lung adenocarcinoma. Mol Cell Proteomics 15: 2396-2410, 2016.

10. Rice TW: Esophageal cancer staging. Korean J Thorac Cardiovasc Surg 48: 157-163, 2015.

11. Young J, Badgery-Parker T, Dobbins T, Jorgensen M, Gibbs P, Faragher I, Jones I and Currow D: Comparison of ECOG/WHO performance status and ASA score as a measure of functional status. J Pain Symptom Manage 49: 258-264, 2015.

12. Bandaranayake AD, Correnti C, Ryu BY, Brault M, Strong RK and Rawlings DJ: Daedalus: A robust, turnkey platform for rapid production of decigram quantities of active recombinant proteins in human cell lines using novel lentiviral vectors. Nucleic Acids Res 39: e143, 2011.

13. Livak KJ and Schmittgen TD: Analysis of relative gene expression data using real-time quantitative PCR and the 2(-Delta DeltaC (T)) method. Methods 25: 402-408, 2001.

14. Ohashi S, Miyamoto S, Kikuchi O, Goto T, Amanuma Y and Muto M: Recent advances from basic and clinical studies of esophageal squamous cell carcinoma. Gastroenterology 149: $1700-1715,2015$ 
15. Herskovic A, Russell W, Liptay M, Fidler MJ and Al-Sarraf M: Esophageal carcinoma advances intreatment results for locally advanced disease: Review. Ann Oncol 23: 1095-1103, 2012.

16. Li BZ, Chen ZL, Shi SS, Feng XL, Tan XG, Zhou F and He J: Overexpression of $\mathrm{Cdc} 25 \mathrm{C}$ predicts response to radiotherapy and survival in esophageal squamous cell carcinoma patients treated with radiotherapy followed by surgery. Chin J Cancer 32: 403-409, 2013

17. Sugase T, Takahashi T, Serada S, Fujimoto M, Hiramatsu K, Ohkawara T, Tanaka K, Miyazaki Y,Makino T, Kurokawa Y, et al: SOCS1 gene therapy improves radiosensitivity and enhances irradiation-induced DNA damage in esophageal squamous cell carcinoma. Cancer Res 77: 6975-6986, 2017.

18. Tamaoki M, Komatsuzaki R, Komatsu M, Minashi K, Aoyagi K, Nishimura T, Chiwaki F, Hiroki T, Daiko H, Morishita K, et al: Multiple roles of single-minded 2 in esophageal squamous cell carcinoma and its clinical implications. Cancer Sci 109: 1121-1134, 2018

19. Shigaki H, Baba Y, Watanabe M, Murata A, Ishimoto T, Iwatsuki M, Iwagami S, Nosho K and Baba H: PIK3CA mutation is associated with a favorable prognosis among patients with curatively resected esophageal squamous cell carcinoma. Clin Cancer Res 19: 2451-2459, 2013.

20. Hannigan GE, Leung-Hagesteijn C, Fitz-Gibbon L, Coppolino MG, Radeva G, Filmus J, Bell JC and Dedhar S: Regulation of cell adhesion and anchorage-dependent growth by a new beta 1-integrin-linked protein kinase. Nature 379: 91-96, 1996.

21. Wong RP, Ng P, Dedhar S and Li G: The role of integrin-linked kinase in melanoma cell migration, invasion and tumor growth. Mol Cancer Ther 6: 1692-1700, 2007.
22. Zhuang X, Lv M, Zhong Z, Zhang L, Jiang R and Chen J: Interplay between intergrin-linked kinase and ribonuclease inhibitor affects growth and metastasis of bladder cancer through signaling ILK pathways. J Exp Clin Cancer Res 35: 130, 2016.

23. Shen H, Ma JL, Zhang Y, Deng GL, Qu YL, Wu XL, He JX,Zhang S and Zeng S: Integrin-linked kinase overexpression promotes epithelial-mesenchymal transition via nuclear factor- $\kappa \mathrm{B}$ signaling in colorectal cancer cells. World J Gastroenterol 22: 3969-3977, 2016.

24. Driver GA and Veale RB: Modulation of integrin-linked kinase (ILK) expression in human oesophageal squamous cell carcinoma cell lines by the EGF and TGFbetal growth factors. Cancer Cell Int 6: 12, 2006.

25. Mohamed MS, Bishr MK, Almutairi FM and Ali AG: Inhibitors of apoptosis: Clinical implications in cancer. Apoptosis 22: 1487-1509, 2017.

26. Duxbury MS, Ito H, Benoit E, Waseem T, Ashley SW and Whang EE: RNA interference demonstrates a novel role for integrin-linked kinase as a determinant of pancreatic adenocarcinoma cell gemcitabine chemoresistance. Clin Cancer Res 11: 3433-839, 2005.

27. Lanvin O, Monferran S, Delmas C, Couderc B, Toulas C and Cohen-Jonathan-Moyal E: Radiation-induced mitotic cell death and glioblastoma radioresistance: A new regulating pathway controlled by integrin-linked kinase, hypoxia-inducible factor 1 alpha and survivin in U87 cells. Eur J Cancer 49: 2884-2891, 2013.

This work is licensed under a Creative Commons Attribution-NonCommercial-NoDerivatives 4.0 International (CC BY-NC-ND 4.0) License. 